\title{
Relevance of Volume and Surface Plasma Generation of Negative Ions in Gas Discharges
}

\author{
V. Dudnikov \\ Brookhaven Technology Group, Inc., NY, USA
}

\begin{abstract}
The relative contribution of volume and surface-plasma generation of extracted $\mathrm{H}^{-}$ions in gas discharge sources is analyzed. By present time, it is well known that surface-plasma generation of extracted $\mathrm{H}^{-}$ion is dominate above volume processes in discharges with admixture of cesium or others catalysts with low ionization potential. From the analysis presented below, it follows that contrary to the standard opinion repeated in tens of publications, in the optimized discharge sources without cesium and small currents of accompanying electrons, named by authors as "pure volume sources", a surface-plasma generation of extracted $\mathrm{H}^{-}$ion also dominate above volume processes. For the effective generation of $\mathrm{H}^{-}$ion beams in discharge without cesium, it is necessary to optimize surface-plasma generation of extracted $\mathrm{H}^{-}, \mathrm{D}^{-}$ion that, as a rule, leads to suppression of volume production. Such optimization allows considerably improving characteristics of $\mathrm{H}^{-}, \mathrm{D}^{-}$sources for accelerators and for neutral beam injectors in magnetic confinement fusion.
\end{abstract}

\section{INTRODUCTION}

In describing negative ion generation in sources with direct extraction of beams from the discharge two mechanisms of $\mathrm{H}^{-}$ion generation, volume and surface-plasma are discussed $[1,2,3,4,5,6,7,8,9,13]$. Volume generation of negative ions (VG NI) is provided by reactions occurring at collisions of electrons with molecules and molecular ions in the plasma volume to what the name of this mechanism is connected. Surface-plasma generation of negative ions (SPG NI) is provided by reactions occurring at interaction of plasma particles with the surface of electrodes that serves the basis for the choice of the name to these processes.

The basic reaction of volume generation of negative ions in plasma is dissociative attachment [1]. In this reaction the electron is captured by a molecule in metastable autoionization state (analogue of nuclear reaction through a compound nucleus), which can decay with dissociation into a negative ion and a neutral fragment, or to repulse out the electron with transition of the molecule in the excited state. The probability of negative ion generation strongly depends on time of fragments separation, i.e. on relative velocities of fragments or excitation of vibrational-rotational states. In its ground state, the cross section of $\mathrm{H}_{2}$ molecule is very small $\left(10^{-21} \mathrm{~cm}^{2}\right.$ with energy of electrons above $3.7 \mathrm{eV}$ ). The cross section of dissociative attachment for deuterium molecules is $2 \cdot 10^{3}$ times less, i.e. a strong isotopic effect is observed. Polar dissociation - dividing of a molecule into positive and negative ions has a greater cross section $\left(10^{-20} \mathrm{~cm}^{2}\right)$, but also higher threshold energy $(17.2 \mathrm{eV})$, that makes this process inefficient in cold plasma. The cross section of destruction of negative ions by electrons at these energies $3 \cdot 10^{-15} \mathrm{~cm}^{2}$, cross section of destruction in collisions with ions $\sim 10^{-13} \mathrm{~cm}^{2}$ is many orders higher than cross sections of generation. For these reasons calculated concentration of $\mathrm{H}^{-}$ions in gas discharge plasma should be very low. In real discharges the concentration of $\mathrm{H}^{-}$ions 
appeared to be much greater than the calculated one, with the account of dissociative attachment to molecules in the ground state and dissociative recombination. In works $[10,11]$, it has been noted that dissociative attachment to vibrationally and rotationally excited molecules has much greater cross sections and lower threshold energy. This circumstance can explain the increased concentration of $\mathrm{H}^{-}$ions in gas discharges.

The review of the situation with $\mathrm{H}^{-}$ion extraction from various discharges by 1973 is given in [12]. Along side with the intensity $\mathrm{I}^{-}$of $\mathrm{H}^{-}$ion beams the intensity of accompanying electron beam Ie is of great significance. From a duoplasmatron with axial extraction (standard ion source for positive ion production by ionization in plasma), by this time up to $0.07 \mathrm{~mA}$ of $\mathrm{H}^{-}$current was obtained at electron current $65 \mathrm{~mA}$, the ratio is $\gamma=\mathrm{Ie} / \mathrm{I}^{-} \sim 1000$. From a duoplasmatron with a displaced emission aperture, up to $2.2 \mathrm{~mA}$ of $\mathrm{H}^{-}$ions was obtained at electron current $650 \mathrm{~mA}$, the ratio is $\gamma \sim 300$. From duoplasmatron with the tubular discharge, up to $6 \mathrm{~mA}$ of $\mathrm{H}$ - ions was obtained at electron current 90 $\mathrm{mA}$, the ratio is $\gamma \sim 15$. In the Ehler's type ion source with a Penning discharge up to 4.6 $\mathrm{mA}$ of $\mathrm{H}$ - was extracted along with 5 times higher electron current. From a planotron (magnetron) type source with magnetron discharge, up to $22 \mathrm{~mA}$ of $\mathrm{H}^{-}$ions was obtained at electron current $100 \mathrm{~mA}$, the ratio is $\gamma \sim 4-5$. These values of $\mathrm{H}^{-}$currents could be explained by the generation of $\mathrm{H}^{-}$ions in volume of plasma due to dissociative attachment of electrons to vibrationally and rotationally excited molecules in plasma volume. For this reason these sources were named volume sources and it was considered in a later review $[1,13]$ that volume generation of $\mathrm{H}^{-}$ions is dominated in them. The importance of SPG NI in discharges without cesium was marked in references $[3,4,15,16,17,24,25]$. Now, there is additional evidence to conclude that the increase of the $\mathrm{H}^{-}$ion current and improvement in the ratio of electron current to $\mathrm{H}^{-}$ion current, in this case, is connected with a reduction of the contribution of volume generation and domination of surface-plasma generation.

\section{Surface-plasma negative ion sources}

The situation with negative ion production has cardinally changed after observation in 1971 of substantial enhancement of negative ion emission after adding cesium to the discharge (cesium catalysis) [14,15,16,17,25]. By adding cesium vapor into the gas discharge chamber of an ion source and activation of electrodes, the intensity of $\mathrm{H}^{-}$ion beam extracted from the discharge has increased considerably. With the cesium, additional it was possible to essentially lower the flow of gas into a source and the flow of accompanying electrons has decreased considerably. The intensity of coextracted electrons became even less than $\mathrm{H}^{-}$ion current. For this the density of electrons should become much less than the density of $\mathrm{H}^{-}$ions near the emission surface. Such behavior of emission of $\mathrm{H}^{-}$ions and electrons did not find an explanation within the framework of known elementary processes in plasma volume. At the registration of energetic spectra of $\mathrm{H}^{-}$ions from the discharge in planotron, the ions accelerated by discharge voltage (originated on the cathode) and the ions formed in the anode area $[15,16,17,25]$ have been detected. On the basis of these experiments, a conclusion has been made that the increased efficiency of $\mathrm{H}^{-}$ion generation in the discharge with cesium adding is caused by a substantial increase in the emission of negative ions from the surface bombarded by plasma particles. Adsorption of cesium lowers surface work function and this increases 
the probability of sputtered and reflected particles escaping in the form of negative ions. This probability increases with the decrease of work function and increase in velocity of particles moving away from the surface. The theory of negative ionization of particles at collision with a surface has been developed in works $[17,18]$. Emission of negative ions rises with the increase in negative potential of the electrode contact with plasma, because energy and intensity and energy of positive ions bombarding a surface increases therefore, the quantity

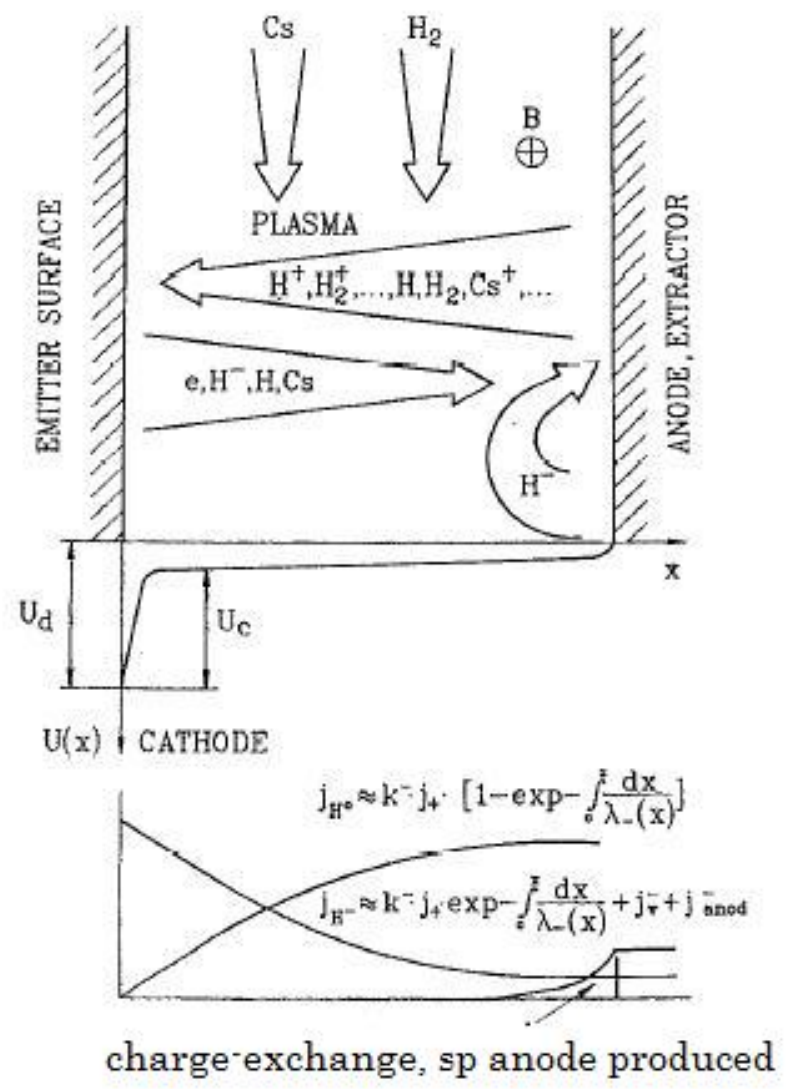

Figure 1. Schematic illustration of surface-plasma negative ion generation

of the sputtered and reflected particles increases, and so does the velocity in which they move away from the surface. Besides, the decrease of potential near the electrode accelerates emitted negative ions without a space charge limitation. It also increases the free path of ions in plasma without destruction and allows extracting them through the emission aperture. Cesium is locked on the surface of negative electrode as it comes back from plasma in the form of ions. Surfaces with a potential close to the potential of plasma are also bombarded by fast plasma particles and emit negative ions. The efficiency of negative ion generation on these surfaces is lower than on electrodes with negative potential, but can be high enough. The discovered mechanism of effective negative ion generation has been named the surface-plasma mechanism of negative ion generation because its functioning is based on interaction of plasma particles with a surface and optimization of this process defines characteristics of negative ion generation. The 
surface-plasma generation (SPG) of negative ions is schematically represented in Figure 1. Ion sources based on this process have been named surface-plasma sources of negative ions (SPS). Rather quickly emission density of $\mathrm{H}^{-}$beams from SPS was increased up to

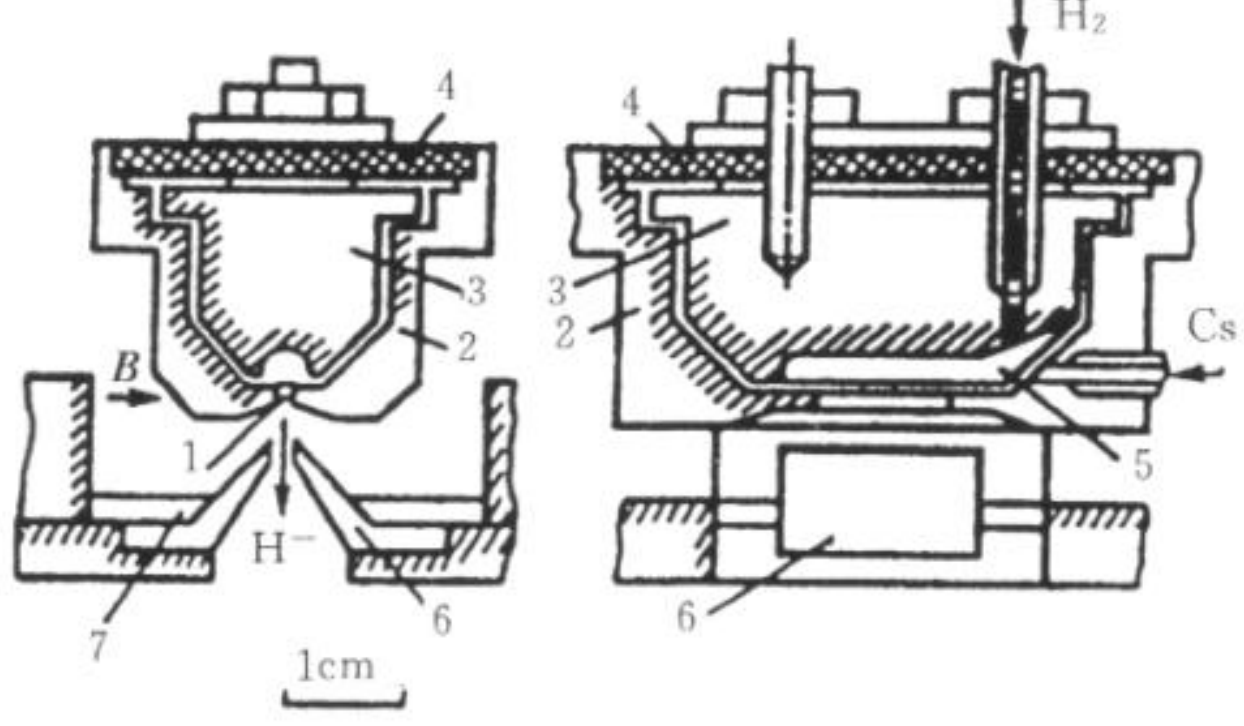

Figure 2. Schematic of Semiplanotron SPS [15].

1- emission aperture; 2- anode; 3-cathode; 4-cathode insulator; 5-discharge channel; 6- extractor; 7- magnet with magnetic insertions.

$3.7 \mathrm{~A} / \mathrm{cm}^{2}$, and after the development of geometrical focusing up to $8 \mathrm{~A} / \mathrm{cm}^{2}$. Various versions of SPS with surface-plasma generation of negative ions on the cathode, on the special emitter or on the anode of the discharge (anode SPG) have been developed. Probably most clear, the features of SPG NI is displayed in semiplanotron. A schematic of semiplanotron SPS [2,15,16] is given in Figure 2. The discharge in crossed Ex B fields is supported between the cathode (3) and the anode (2) in narrow (2-3 mm) semicylindrical discharge channel (5), opposite to the emission aperture (1). The discharge is ignited in a deeper grove in the right end of the cathode where working gas and cesium are injected. Plasma drifts in the crossed fields from the right to the left. Electrons oscillate along the magnetic field between the walls of a semi-cylindrical discharge channel, and positive ions bombard its surface, initiating emission of the sputtered and reflected particles. Part of these particles leaves the surface in the form of negative ions. The probability of particles escaping as negative ions increases essentially at the reduction of surface work function due to adsorption of cesium or other substances with low ionization potential. Negative ions are accelerated by a potential difference between surface and plasma and are focused on the emission aperture due to the cylindrical form of the emitter. During the moving through the plasma part of ions loses electrons in collisions with plasma particles and converts in fast neutrals, as shown in the scheme of Figure 1. Part of fast negative ions transfers electron to cold atoms, transforming to cold negative ions. This charge- exchange cooling of negative ions increases beam brightness. Shielding of an emission aperture by equi-potential grove (collar) and a strong transverse magnetic field form the magnetic filter, suppressing plasma diffusion to the emission aperture and extraction of accompanying electrons. The walls of equi-potential cavity are 
bombarded by fast ions and atoms from the cathode and by less energetic (with energy 5$10 \mathrm{eV}$ ) particles from the discharge.
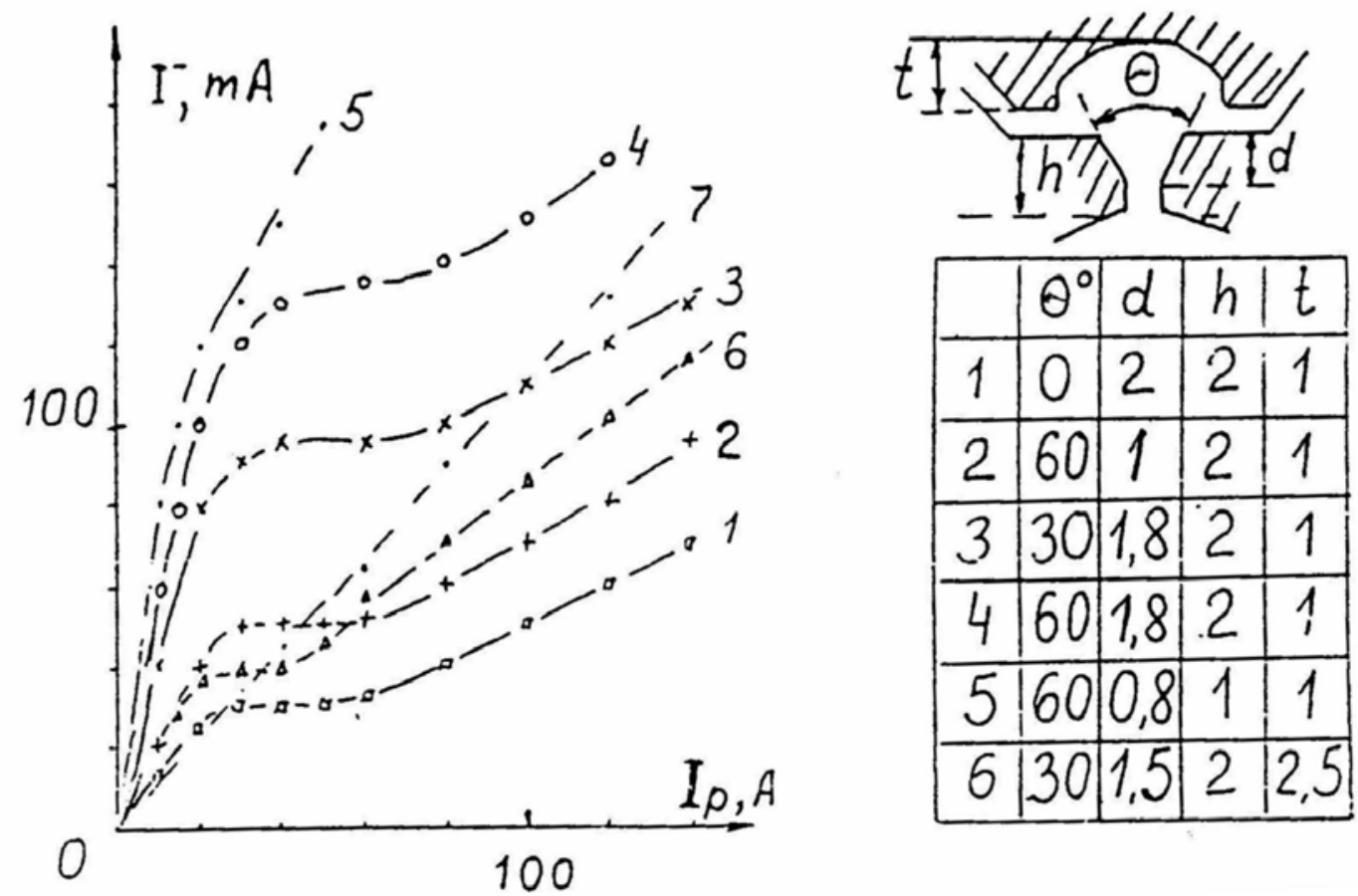

Figure 3. Dependence of $H^{-}$current on the discharge current at different geometries of discharge channel and magnetic filter in semiplanotrons. Dependence (7) is obtained in SPS with Penning discharge.

This bombardment causes emission of negative ions from the anode surface around the emission aperture (anode SPG, shown on Fig. 1). Low density of electrons in this area and low electron temperature promote survival and effective extraction of negative ions from this area. Emission characteristics of semiplanotron at various configurations of the discharge channel and the magnetic filter are shown in Figure 3. Dependences of the intensity of $\mathrm{H}^{-}$ion beam on the discharge current have the $\mathrm{N}$-shaped form with three sections: linear growth at small discharge currents, saturation or a falling section at medium currents, and linear, but slow growth at the high currents. Linear dependence (7) is obtained in SPS with Penning discharge. At small discharge currents most of extracted NI is provided by SPG on the cathode. In this section the efficiency of SPG is the highest (up to $6 \mathrm{~mA}$ on $1 \mathrm{~A}$ of discharge current at discharge voltage of $100 \mathrm{~V}$, up to $60 \mathrm{~mA}$ per $\mathrm{kW}$ ). With the increase in discharge current the flow of NI from the cathode is attenuated by destructions in plasma, and less effective anode SPG cannot compensate this attenuation that forms a falling section. At the high discharge currents, linear growth of NI current is provided by anode SPG. Emission of positive ions is much less than the emission of NI; the contribution of volume generation of NI is relatively low. Anode SPG provides linear dependence of negative ion current on discharge current in the Penning SPS shown under number (7). The current of accompanying electrons in these 
measurements was less than the negative ion current in normal magnetic fields $\mathrm{B} \sim 1 \mathrm{kG}$. In weak fields $(\mathrm{B} \sim 0.1 \mathrm{kG})$, the electron current could be 10-20 times greater then the negative ion current. In semiplanotron SPG of negative ions is realized most effectively,
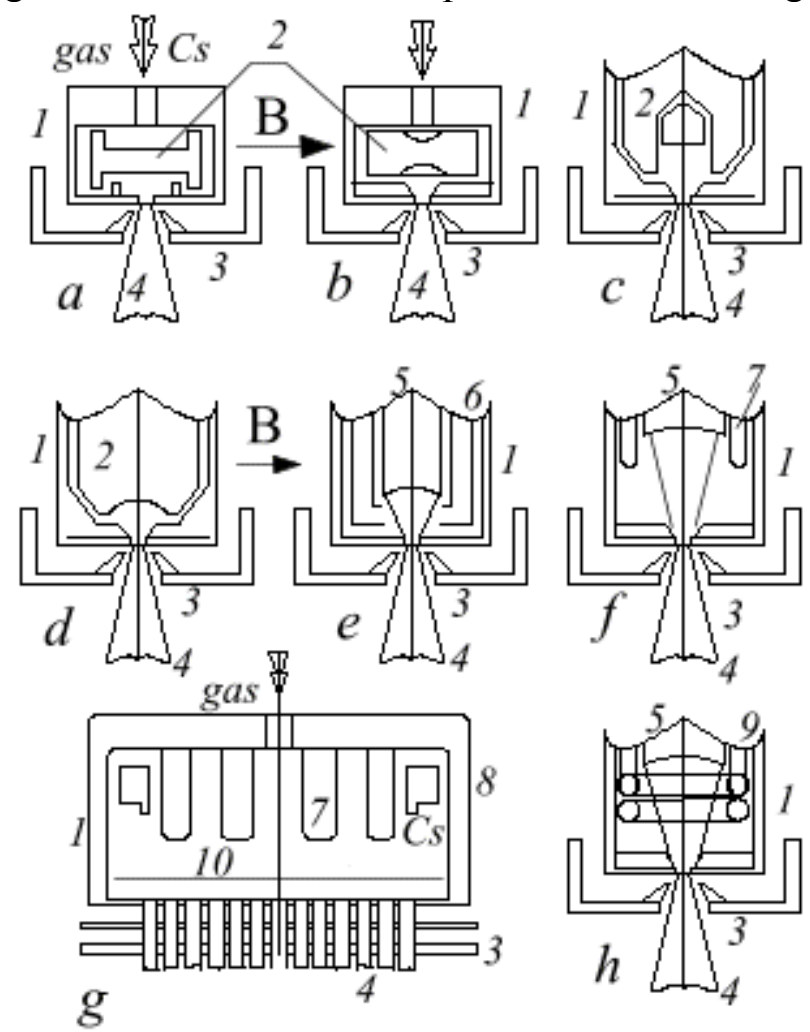

Figure 4. Electrode configuration for basic versions of SPS.

(a) Planotron (flat magnetron) with the flat cathode-emitter; (b) Planotron with geometrical focusing (cylindrical and spherical); (c) SPS with Penning discharge (Dudnikov type source); (d) semiplanotron; (e) SPS with the hollow cathode and the independent emitter; (f) SPS with large volume and with the emitter; $(g)$ large volume SPS with anode generation of NI; (h) large volume with RF generation of plasma. 1anode (the discharge chamber); 2-cold cathode-emitter; 3-extractor with magnetic system; 4-NI beam; 5-emitter with negative displacement; 6-hollow cathode; 7thermocathodes; 8-magnetic wall; 9-RF antenna (coil); 10-magnetic filter. Working gas and cesium are brought into the gas discharge of SPS.

Presently, many versions of SPS, optimized for various applications, have been developed. Classification of various versions of SPS is presented in [15, 16]. Configurations of some SPS are shown in Figure 4. Currents of accompanying electrons in SPS are comparable to $\mathrm{H}^{-}$ion currents, or are less, that is $\gamma_{\mathrm{sp}}<\sim 1$, whereas at volume generation of negative ions $\gamma_{\mathrm{v}} \sim 500-1000$. Estimations of the relative contribution of volume and surface-plasma generation of negative ions in various discharges are presented in many publications [26,27,28,29,31,32]. By present time it became a 
commonly supported opinion, that surface-plasma generation of negative ions (SPG) absolutely dominates in discharges with addition of cesium, barium [1-8,15,16,25,28]. However, sources with discharges without cesium or other catalytic additives with low potential of ionization were, until recently, referred to as sources with volume generation of negative ions [1-9,13,22,23,27,28,30].

\section{Tandem large volume negative ion sources}

Tandem ion sources with a magnetic filter and magnetic cusp wall, used for the production of positive ion beams with a high proton component, have been adapted for optimization of volume generation of $\mathrm{H}^{-}$ions [13,21,22]. In these sources plasma is generated in a driver zone by DC filament discharge or by RF discharge in a chamber with a magnetic cusp wall. The plasma diffusion to an emission aperture (into the area of extraction) is suppressed by a transverse magnetic field of the filter dividing the source into two zones. The configuration of such source is shown in Figure 4, (g). It is believed that in the generation zone fast electrons excite molecules in high vibration and rotation states, which diffuse to the extraction area with cold electrons. In the extraction area $\mathrm{H}^{-}$ ions are formed by dissociative attachment of cold $\sim 1 \mathrm{eV}$ electrons to the excited molecules. Formed $\mathrm{H}^{-}$ions are extracted together with electrons through an emission aperture and formed into a beam. At low electron temperature the rate of negative ions destruction decreases and they can be extracted from a larger generation area. Features of these sources were discussed in many publications, references to which are presented in reviews $[1,6,7,8,9,13,20,31,32]$. It is considered that the increase of proton components in tandem sources is caused by effective dissociation of molecular ions in the area of the magnetic filter by cold electrons. Probably, it is more essential that the magnetic filter suppresses the plasma transportation to the emission aperture, and to obtain previous emission current density it is necessary to have much greater plasma density and power density in the discharge contributing to more completed dissociation of molecules. It is necessary to note that the same configuration of the discharge, with a dense plasma generation zone separated from the extraction area with cold plasma of low density by the magnetic filter and a collar (anode ribs), was used in the first versions of Ehlers-type source and in the first versions of compact SPS [15,16,17,23,24,25]. Due to empirical optimization of tandem sources, it was possible to obtain significant currents of $\mathrm{H}^{-}$ions at rather small currents of accompanying electrons. The parameters of tandem sources made and researched in different laboratories are shown in Table 1 from [7]. These sources typically have $\mathrm{H}^{-}$ion current $\mathrm{I}^{-}$up to $38 \mathrm{~mA}$ with emission current density of $\mathrm{J} \sim 0.1$ $\mathrm{A} / \mathrm{cm}^{2}$. The accompanying electron current to $\mathrm{H}^{-}$ion current ratio Ie $/ \mathrm{I}^{-}$varies from $\gamma=26$ down to 4. The last value is close to being obtained in SPS with cesium.

In the sources presented in Table 1, which authors classify as volume sources, were obtained by empirical optimization relatively high emission current density and small ratios of electron current to a $\mathrm{H}^{-}$ion current (up to 4) and consequently, low density of electrons on the emission surface and low rate of volume generation of negative ions. This permits the assertion, that in optimized $\mathrm{H}^{-}$ion sources without cesium with low electron currents, the surface-plasma generation of negative ions dominates, as well as in discharges with cesium or others catalytic admixtures with low ionization potential. 


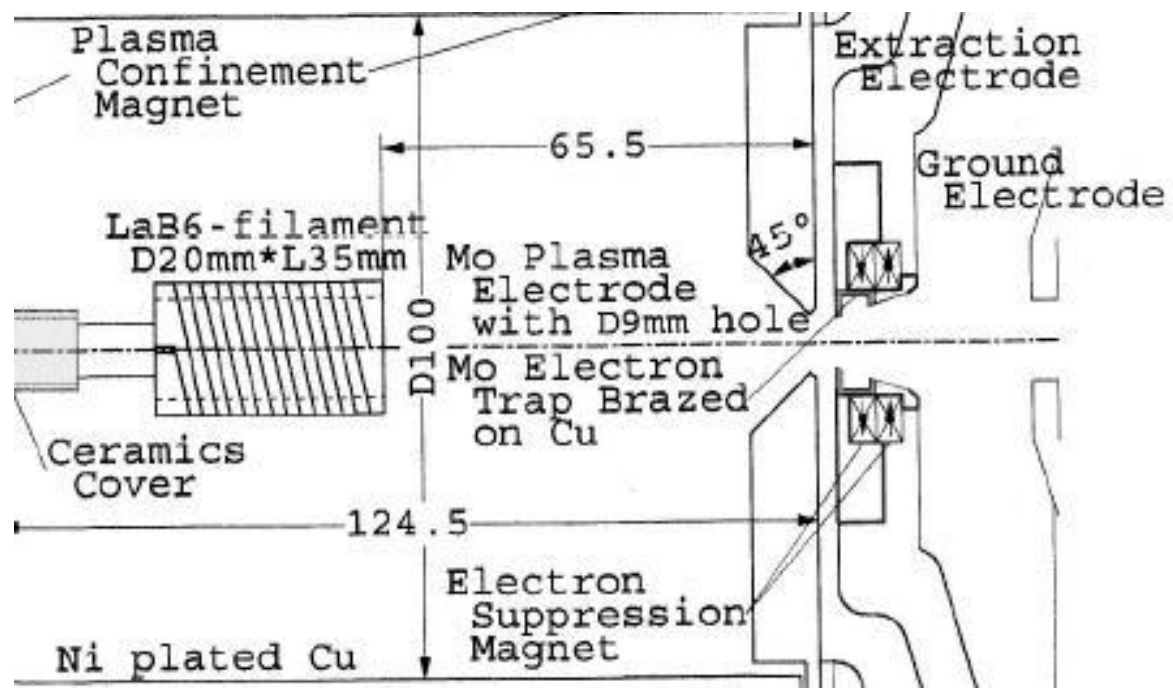

Figure 5. Design of the KEK/ JAERI Large Volume SPS from [29].

Table 1 .Tandem sources with the discharge without cesium

\begin{tabular}{|c|c|c|c|c|c|}
\hline Source & $\begin{array}{c}\mathrm{I}_{\mathrm{H}-} \\
(\mathrm{mA}\end{array}$ & $\begin{array}{c}\mathrm{P}_{\mathrm{d}} \\
(\mathrm{kW})\end{array}$ & $\begin{array}{c}\mathrm{P}_{\text {eff }} \\
(\mathrm{mA} / \mathrm{kW}\end{array}$ & $\mathrm{Ie} / \mathrm{I}_{\mathrm{H}-}$ & $\mathrm{df}(\%)$ \\
\hline $\mathrm{BNL}\left(\mathrm{H}_{2}\right)$ & 35 & $\begin{array}{c}25(\mathrm{~W} \\
\text { cathode) }\end{array}$ & 1.40 & 20 & 0.5 \\
\hline $\begin{array}{c}\text { DESY } \\
\left(\mathrm{H}_{2}\right)\end{array}$ & 38 & $\begin{array}{l}27(\mathrm{RF} \\
2 \mathrm{MHz})\end{array}$ & 1.41 & 26 & 0.08 \\
\hline $\begin{array}{c}\text { JAERI } \\
\left(\mathrm{H}_{2}\right)\end{array}$ & 14 & $\begin{array}{c}30(\mathrm{~W} \\
\text { cathode) }\end{array}$ & 0.47 & 10 & 5 \\
\hline $\begin{array}{c}\mathrm{SSC} \\
\left(\mathrm{H}_{2}\right)\end{array}$ & 30 & $\begin{array}{l}40(\mathrm{RF} \\
2 \mathrm{MHz})\end{array}$ & 0.75 & 20 & 0.35 \\
\hline $\begin{array}{c}\text { ANL } \\
\left(\mathrm{H}_{2}+\mathrm{Ta}\right)\end{array}$ & $4-5$ & $\begin{array}{l}0.7(\mathrm{ECR} \\
2.45 \mathrm{GHz})\end{array}$ & $5.7-7.1$ & 20 & 100 \\
\hline $\begin{array}{l}\text { TRIUMF } \\
\left(\mathrm{H}_{2}+\mathrm{Ta}\right)\end{array}$ & 20 & $\begin{array}{c}4.8(\mathrm{Ta} \\
\text { cathode) }\end{array}$ & 4.2 & 4 & 100 \\
\hline
\end{tabular}

In tandem source described in [29], which the authors firstly developed as volume, subsequent optimization of SPG on plasma electrode in discharges without cesium has allowed a considerably increase in $\mathrm{H}^{-}$ion current (to $38 \mathrm{~mA}$ ) and a reduction in electron current. Design of this large volume source is shown in Figure 5. Increase of H- current and suppression of electrons is reached by optimization of plasma electrode (PE) surface near an emission aperture. Optimization of PE temperature and activation by discharge was very important for enhance a SPG of $\mathrm{H}$ - ions. These experiments present a good confirmation of domination of SPG in the optimized discharges without cesium in tandem large volume sources. 


\section{Ion Sources with discharges in crossed fields}

In this section we shall consider features of negative ion generation in compact sources with high discharge current density in crossed fields. After obtaining in planotron with cesium of $\mathrm{H}^{-}$beam with emission ion current density up to $3.7 \mathrm{~A} / \mathrm{cm}^{2}[15,17,25]$ in the Institute of Nuclear Physics, Novosibirsk a special "pure" planorton without traces of cesium or other alkaline admixtures, but with "thick" cathode was manufactured. The scheme of this source is shown in Figure 4(a). The dependence of $\mathrm{H}^{-}$emission current density on the discharge current in this source before admixture of cesium and with cesium is shown in Figure 6. From this source with the discharge in pure hydrogen after activation by high current discharges had been obtained $\mathrm{H}^{-}$beam with emission density up to $0.75 \mathrm{~A} / \mathrm{cm}^{2}$. This current is much greater than that expected from volume generation. The electron current to $\mathrm{H}^{-}$ion current ratio $\gamma$ was up to $4[17,25]$. When the optimum supply of cesium was reached, the emission current density increased to 3.7 $\mathrm{A} / \mathrm{cm}^{2}$. On the basis of these results, a conclusion has been made that in this source without cesium, high efficiency of negative ion generation is also caused by surfaceplasma generation of negative ions, as well as in discharges with cesium. The discharge voltage in these experiments did not go down to $150-100 \mathrm{~V}$ as in discharges with cesium adding, but was a little bit below standard for hydrogen discharges voltage of 400-500 V. It has been assumed, that surface-plasma generation of $\mathrm{H}^{-}$ions increased due to decrease of electrode work function, related to the diffusion of potassium and other alkaline metals admixture from the volume of molybdenum on the surface at intense heating. Usually refractory metals such as tungsten, molybdenum, tantalum, etc. contain admixture of alkaline metals with high concentration. A small decrease in work function, practically not influencing the discharge voltage, can increase essentially SPG and make it the dominating mechanism of negative ion generation. Such decrease in work function can be provided by uncontrollable alkaline pollution; for example, finger prints, drops of a saliva, etc. Also for example the enamel used for insulation of internal RF antenna coil in "volume" sources contains $15 \%$ of potassium by weight [6,7]. Sputtering/deposition of this coating are enough for catalysis of SPG of $\mathrm{H}^{-}$ions. It is necessary to note that after addition of cesium or other catalysts, they are implanted into electrodes and again diffused to the surface at activation by the discharge. It is not simple to clean the source of traces of these impurities.

An attempt to obtain an intense beam without cesium has been undertaken in works [26, 27] using the discharge with a cathode from lanthanum hexaboride in Dudnikov-type source with Penning discharge. A schematic of this source is shown in Figure 4 (c).With discharge current $50 \mathrm{~A}$ and emission aperture of $1 \mathrm{~mm}$ diameter, there have been received $\mathrm{H}^{-}$ion beam with emission current density of $0.35 \mathrm{~A} / \mathrm{cm}^{2}$ and with accompanying electron current to $\mathrm{H}^{-}$ion current ratio of up to $\gamma \sim 4$. On the basis of indirect evidences in this work, a conclusion has been made that in these conditions $\mathrm{H}^{-}$ions are formed due to volume processes.

Undoubtedly, in these conditions $\mathrm{H}^{-}$ions were produced basically due to SPG on the surface of plasma electrode (the anode) near emission aperture (anode SPG). Benefiting it is the fact that the current of $\mathrm{H}^{-}$ions linear increased at the increase of magnetic field up to $7 \mathrm{kG}$ when the flow of electrons in the extraction area should have decreased many times, and volume generation should have been suppressed. For SPG, electrons are not 


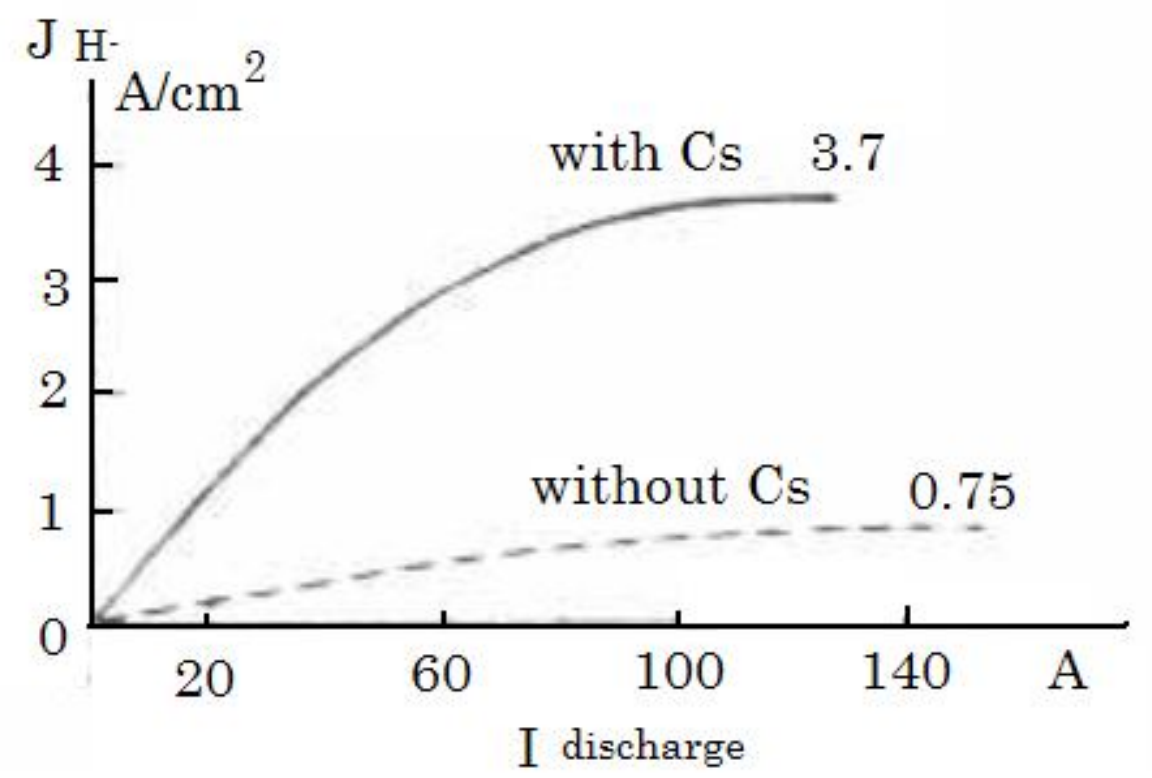

Figure 6. Dependence of emission $H^{-}$ion current density on discharge current in planorton with pure hydrogen and cesium adding.

needed in the extraction area; it is enough to have bombardment of the surface by atoms with energies higher than threshold $\varphi-A=4.5-0.75 \mathrm{eV}$. Suppression of electron flow into extraction area by the magnetic field only reduces the destruction of negative ions by electrons and suppresses extraction of accompanying electrons. Almost full dissociation of molecules into atoms, caused by high discharge current density, suppresses volume generation of negative ions, but optimizes SPG.

Similar behavior has been observed in the research of $\mathrm{H}^{-}$ion emission from Ehlers source with an insulated plasma electrode [23]. A schematic of this source is shown in Figure 7. The diameter of the discharge column with electron oscillation is $4.8 \mathrm{~mm}$; the diameter of the plasma electrode is $9.6 \mathrm{~mm}$. The output of $\mathrm{H}^{-}$ions rose at an increase of magnetic field up to $5 \mathrm{kG}$. In usual conditions with the potential of plasma electrode equal to anode potential, as well as in the previous source, up to $4.6 \mathrm{~mA}$ of $\mathrm{H}^{-}$ions and $20 \mathrm{~mA}$ of electrons were extracted. At the decrease of a plasma electrode potential down to $-6 \mathrm{~V}$, emission of $\mathrm{H}^{-}$ions increased 2 times to $9.7 \mathrm{~mA}$ (emission current density up to 100 $\mathrm{mA} / \mathrm{cm}^{2}$ ), and electron current up to $100 \mathrm{~mA}$. At the increase of a plasma electrode potential of up to $+5 \mathrm{~V}$, emission of $\mathrm{H}^{-}$ions decreased to $3 \mathrm{~mA}$ (emission current density up to $30 \mathrm{~mA} / \mathrm{cm}^{2}$ ) and electron current up to $15 \mathrm{~mA}$. At negative biasing of plasma electrode relative to the anode, the current of positive ions was almost 2 times less than the current of $\mathrm{H}^{-}$ions. At positive plasma electrode, the current of positive ions exceeded the current of $\mathrm{H}^{-}$ions approximately 2 times. The protons consumption in positive ion beam was $90 \%, \mathrm{H}_{2}{ }^{+} 4 \%, \mathrm{H}_{3}{ }^{+} 6 \%$. Dependences of $\mathrm{H}^{-}$and $\mathrm{D}^{-}$current on gas flux had characteristic maxima with exponential attenuation at the larger gas flows. This behavior 


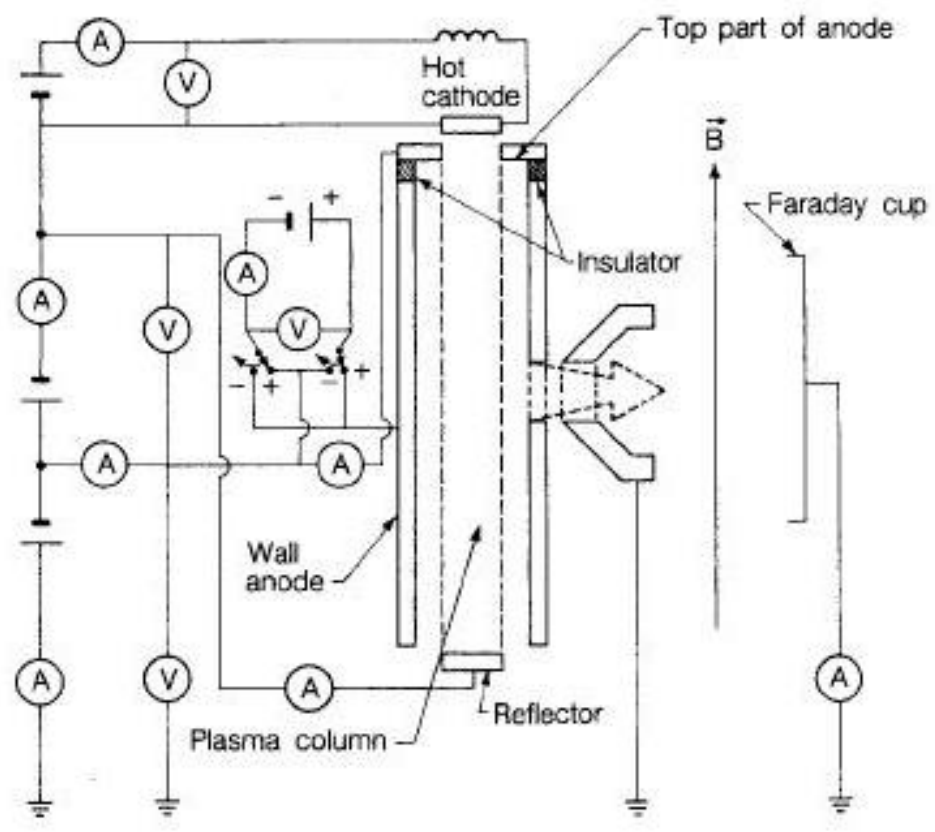

Figure 7. Schematic of modified Ehlers ion source with electron oscillation in magnetic field and insulated plasma electrode [23].

is explained by the destruction of negative ions upon leaving gas after extraction. The maximal current of $\mathrm{D}^{-}$ions equal $4.1 \mathrm{~mA}$ was 2 times less the current of $\mathrm{H}^{-}$ions. Authors concludes, that $\mathrm{H}^{-}$and $\mathrm{D}^{-}$ions were generated by volume processes, but the presented dependences show that volume generation of negative ions should be strongly suppressed. Diffusion of plasma to plasma electrode is strongly suppressed, so the density of positive ions is less than the density of negative ions, so the density of electrons is considerably less than the density of negative ion that is impossible at domination of volume generation. The electron current exceeded the current of $\mathrm{H}^{-}$ions from 5 to 10 times, which also corresponds to significant domination of $\mathrm{H}^{-}$ions density over of electrons density. Gas in the researched conditions is strongly dissociated (90\%), that also suppresses volume generation of negative ions. Increase of negative ion emission at negative biasing on plasma electrode also proves domination of surface-plasma generation of negative ions and their extraction from the surface of a plasma electrode in the discussed discharge without cesium.

Similar research of $\mathrm{H}^{-}$ion production in Ehlers source without cesium and with the additive of cesium was carried out in work [28]. Calculations of $\mathrm{H}^{-}$ion generation in discharges with cesium and without cesium were conducted at the same time. With similar experimental results authors have come to the conclusion, that in discharges without cesium, volume generation of $\mathrm{H}^{-}$ions dominates, and in discharges with cesium SPG dominates. The arguments mentioned above allow the conclusion that in discharges without cesium, SPG is also dominated, but its efficiency is significantly lower than in discharges with cesium. 
The authors of the source with magnetron discharge in longitudinal magnetic field [30] classify it as a volume source. A schematic of this source is shown in Figure 8.

Dependence of extracted H- current and electron current on discharge current are shown in Figure 9. Relatively small electron current to $\mathrm{H}^{-}$ion current ratio $\gamma$

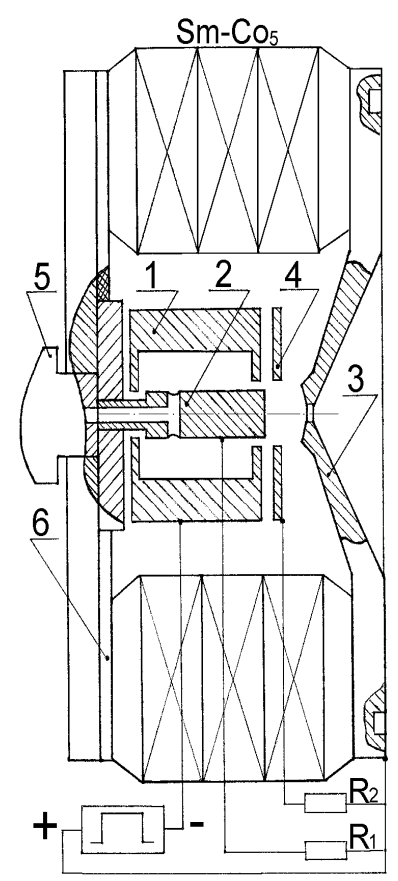

Figure 8. Schematic of ion source with a magnetron discharge in longitudinal magnetic field from [30 ].1-cathode; 2- anode; 3-plasma electrode; 4-intermediate electrode; 5 gas valve; 6- insulating plate.

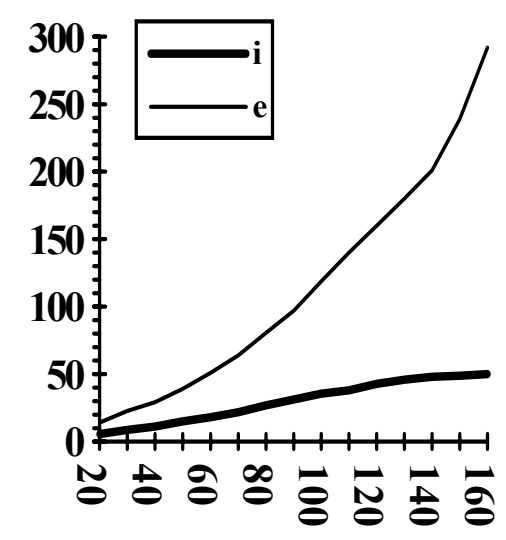

Figure 9. Dependence of $\mathrm{H}$-current (i) and electron current (e) on discharge current from [30].

(10-13) and it decrease to 6 at extraction along magnetic field is a strong evidence of the SPG domination on the plasma electrode. 


\section{Estimations of volume generation contribution into $\mathrm{H}^{-}$ion emission}

Developed in [31] the laser photo-detachment method for measurement of $\mathrm{H}^{-}$ion density and electron density ratio allows registering this ratio reliably. The detection of the fact that $\mathrm{H}^{-}$ion density to electron density ratio is not $10^{-5}$ as it should be according to calculations with dissociative attachment to molecules in the ground state, but is $10 \%$, allowed to hope, that volume processes can be used for intense $\mathrm{H}^{-}$ion beams production in discharges without cesium [11]. In later measurements, this ratio in volume sources remained at level 0.1-0.15 [32]. In special discharges with cesium, it is possible to provide very high $\mathrm{H}^{-}$ion density $\left(10^{13}\right)$ by step by step excitation and dissociative attachment, but the condition that higher electron density is necessary for volume generation of $\mathrm{H}^{-}$ions makes it noncompetitive with SPG, which does not need electrons. It is sufficient to have bombardment of electrode surface by atoms with threshold energies of several $\mathrm{eV}$.

The relative contribution of volume generation $\mathrm{I}_{\mathrm{v}}{ }^{-}$into flux $\mathrm{I}^{-}$of emitted $\mathrm{H}^{-}$ions can be estimated on the basis of electron current $\mathrm{I}_{e}$ to $\mathrm{H}^{-}$ion current $\mathrm{I}^{-}$ratio. To estimate the contribution of volume and surface-plasma generation, divide currents of emitted negative ions $\mathrm{I}^{-}$and electrons $\mathrm{I}_{\mathrm{e}}$ by volume generated $\mathrm{I}_{\mathrm{v}}{ }^{-}, \mathrm{I}_{\mathrm{v}}{ }^{\mathrm{e}}$ and surface-plasma generated $\mathrm{I}_{\mathrm{sp}}^{-}, \mathrm{I}_{\mathrm{sp}}^{\mathrm{e}}$,

$\mathrm{I}^{-}=\mathrm{I}_{\mathrm{v}}{ }^{-}+\mathrm{I}_{\mathrm{sp}}{ }^{-}, \mathrm{I}_{\mathrm{e}}=\mathrm{I}_{\mathrm{v}}{ }^{\mathrm{e}}+\mathrm{I}_{\mathrm{sp}}{ }^{\mathrm{e}}$.

Let us introduce the following designations:

$\gamma=\mathrm{I}_{\mathrm{e}} / \mathrm{I}^{-} ; \mathrm{I}^{-}=\mathrm{I}_{\mathrm{e}} / \gamma \quad \gamma_{\mathrm{v}}=\mathrm{I}_{\mathrm{v}}{ }^{\mathrm{e}} / \mathrm{I}_{\mathrm{v}}{ }^{-} ; \quad \gamma_{\mathrm{sp}}=\mathrm{I}_{\mathrm{sp}}{ }^{\mathrm{e}} / \mathrm{I}_{\mathrm{sp}}{ }^{-} ; \quad \mathrm{I}_{\mathrm{v}}{ }^{-}=\mathrm{I}_{\mathrm{v}}{ }^{\mathrm{e}} / \gamma_{\mathrm{v}} ; \mathrm{I}_{\mathrm{sp}}{ }^{-}=\mathrm{I}_{\mathrm{sp}}{ }^{\mathrm{e}} / \gamma_{\mathrm{sp}} ;$

For the estimation of required volume generation contribution $\beta$ in $\mathrm{H}^{-}$ion emission, we have the following expression:

$\beta=\mathrm{I}_{\mathrm{v}}{ }^{-} /\left(\mathrm{I}_{\mathrm{v}}{ }^{-}+\mathrm{I}_{\mathrm{sp}}{ }^{-}\right)=\mathrm{I}_{\mathrm{v}}{ }^{-} / \mathrm{I}^{-}=\mathrm{I}_{\mathrm{v}}{ }^{\mathrm{e}} / \gamma_{\mathrm{v}}\left(\mathrm{I}_{\mathrm{e}} / \gamma\right)=\mathrm{I}_{\mathrm{e}} / \gamma_{\mathrm{v}}\left(\mathrm{I}_{\mathrm{e}} / \gamma\right)=\gamma / \gamma_{\mathrm{v}}$

At volume generation of $\mathrm{H}^{-}$ions, electron density $\mathrm{n}_{\mathrm{e}}$ to $\mathrm{H}^{-}$ion density $\mathrm{n}$. ratio, $\alpha_{\mathrm{v}}=\mathrm{n}_{\mathrm{e}} / \mathrm{n}$ $\sim 10$ and electron current to $\mathrm{H}^{-}$ion current ratio, during extraction from such plasma should be $\gamma_{\mathrm{v}}=\mathrm{I}_{\mathrm{v}}{ }^{\mathrm{e}} / \mathrm{I}_{\mathrm{v}}{ }^{-} \sim \mathrm{n}_{\mathrm{e}} \mathrm{V}_{\mathrm{e}} / \mathrm{n}_{-} \mathrm{v}^{-} \sim 500-1000\left(\mathrm{v}_{\mathrm{e}}\right.$, $\mathrm{v}^{-}$are electron and $\mathrm{H}^{-}$ion velocities that 50-100 times differ by value). At surface-plasma generation emission of electrons is caused by secondary emission and thermo-emission. Coefficient of secondary ionelectron emission is comparable with coefficient of secondary emission of ions $\mathrm{H}^{-}, \mathrm{K}=0.1$ [33], and the corresponding electron current cannot exceed $\mathrm{H}^{-}$ion current. At bombardment of the emission surface by super-thermal atoms, the secondary electron emission is much less that ion-electron emission. Thermo-emission current from overheating plasma electrode with cesium can be relatively large; but in optimum conditions the accompanying electron current can be made much less than the $\mathrm{H}^{-}$ion current, that is the following ratio corresponds to surface-plasma generation of $\mathrm{H}^{-}$ions: $\gamma_{\mathrm{sp}}=\mathrm{I}_{\mathrm{sp}}{ }^{\mathrm{e}} / \mathrm{I}_{\mathrm{sp}}<\sim 1$. At that, the relative contribution $\beta$ of volume generation of emitted $\mathrm{H}^{-}$ ions is equal to the ratio between real $\gamma$ in the investigated discharge and $\gamma_{v} \sim 500-1000$, 
$\beta=\gamma / \gamma_{\mathrm{v}}$. For discharges with the ratio $\gamma \sim 10$, typical for good "volume" sources, the above estimation for the contribution of volume generation is $\beta \sim 1-2 \%$.

\section{Conclusion}

Analysis of $\mathrm{H}$ - ion emission features from discharges in different ion sources is presented. Conditions for volume and surface plasma generation of $\mathrm{H}^{-}$in gas discharges are coexist. However a relative contribution of VG and SPG in emission of $\mathrm{H}^{-}$and in support of volume $\mathrm{H}^{-}$density can be very different. In discharges with high emission current density a free path of cold $\mathrm{H}^{-}$is very short. In these conditions a volume density of $\mathrm{H}^{-}$is determined by VG. But the production of emitted $\mathrm{H}^{-}$is determined by SPG on the surface of plasma electrode around of emission aperture. For enhance of efficiency of emitted $\mathrm{H}^{-}$production it is necessary an optimization of SPG on the plasma electrode. This can be reached by efficient transformation of gas molecules to flux of hyperthermal atoms with energy of several $\mathrm{eV}$. It is need to use a magnetic filter with a strong magnetic field for strong suppression of electron diffusion to the emission surface. It is useful to use a slit extraction system. It is need to optimize a shape of plasma electrode and thermal property for efficient extraction of formed $\mathrm{H}^{-}$ions. It is need to use an activation of emission surface by discharge and by thermo processing. After such optimization it is possible to produce on emission surface a high density of $\mathrm{H}^{-}$with much lower density of electrons, and suppress electron current up to electron to $\mathrm{H}^{-}$current ratio not large than $\gamma=5-10$ in discharges without cesium. A high efficiency of such optimization was demonstrated in references $[17,29]$. A following decrease of work function of emission surface of plasma electrode by optimal deposition of cesium, or other substances with a low ionization potential is increase stable and reliable an efficiency of anode SPG and all characteristics of negative ion sources.

\section{ACKNOWLEDGMENTS}

The author is grateful of the colleagues Yu. Belchenko, G. Dimov, G. Derevyankin for cooperation in production of basic results, used in this work. I wish to thank Akira Ueno and Paul Farrell for useful discussions.

\section{REFERENCES}

1. H. Zhang, Ion Sources, Springer, 1999.

2. Yu.I.Belchenko, G.I.Dimov, V.G.Dudnikov, et.al, Journal of applied Mechanics and Technical Physics, 28(4), 568-76, (1987).

3. V.Dudnikov, Some effects of surface-plasma mechanism for production of negative ions, BNL 51304,UC-34a, p.137, (1980).

4. Yu.I. Belchenko, Surface negative ion production in ion sources, Rev. Sci. Instrum., 64 (6), 1385 (1993).

5. Charles W. Schmidt, "Review of Negative Hydrogen Ion Sources", Proc. of the 1990 Linear Accelerator Conference, Los Alamos Report (LA-12004-C), 259 (1990). 
6. J.Peters, EPAC'2000. Peters, LINAC' 98, Chicago, 1998. Peters, Rev. Sci. Instrum., 71(2), 1069 (2000).

7. Joseph Sherman and Gary Rouleau, AARAI 02, Denton, TX 2002.

8. R. Welton, Linac 2002 (2002).

9. J.Peters, Rev.Sci.Instrum., 75 (5), (2004).

10. V.Kuchinsky, V.Mishakov, A.Tibilov, A. Shukhtin, Optica I Spektroskopiya, 39 (6), 1043, (1975).

11. M. Bacal, A. M. Bruneteau, W. G. Graham, G. W. Hamilton, and M. Nachman, J.Appl. Phys. 52(3), 1247 (1981).

12. K. Prelec, and Th. Sluyters, Formation of Negative Hydrogen Ions in Direct Extraction Sources, Rev. Sci. Instrum, Vol.44, No.10, (1973).

13. V. Dudnikov, The Method for Negative Ion Production, SU Author Certificate, C1.H013/04, No. 411542, Application, 10 March, 1972, granted 21 Sept.,1973, published 15 Jan.1974, Bul. No 2.

14. V. Dudnikov, Surface-Plasma Method of Negative Ion Production, Doctor Thesis, INP Novosibirsk, 1976 (unpublished).

15. V. Dudnikov, Rev. Sci. Instrum. 63(4),2660 (1992). V. Dudnikov, Rev. Sci. Instrum. 73(2), 992 (2002).

16. Yu. Belchenko, G. Dimov, V. Dudnikov, Izvestia Akademii nauk SSSR, Seriya Fizicheskaya, vol.37, no.12, p.2573-7, Dec.1973, ISSN0367-6765. Translated in: Bulletin of the Akademy of Sciences of the USSR Physical Series, v.37, no.12, p.91-5. 1974, Yu.I. Belchenko, G.I. Dimov, V.G. Dudnikov, Report INP, Novosibirsk, Rep. 66-72, (1972).

17. Michail Kishinevsky, Sov. Phys. Tech. Phys, 45, no.6, 1281 (1975), and 48, no.4, 773 (1978).

18. Leonid Kishinevsky, Isvestia An. SSSR, 38, 392(1974), translated Bul. Acad.Sci. USSR, Phys. Ser. V.38 (1974). Later these calculation were repeated by Cui [H.L Cui, J. Vac. Sci. Technol.,A, 9 (3), 1823 (1991)].

19. J. R. Hiskes, Comments At. Mol. Phys. 19(2), 59(1987).

20. K. W. Ehlers and K. N. Leung, Rev. Sci. Instrum. 53, 1423 (1982).

21. K, N. Leung, K. W. Ehlers, and R. V. Pyle, Rev. Sci. Instrum 56(3), 364(1985).

22. K.Jimbo, K.Ehlers, K.Leung, R.Pyle, Nucl.Inst.Methods, A 248, 282 (1986).

23. Yu. I. Belchenko, G. I. Dimov, and V. G. Dudnikov, ZhTF 43, 1720(1973).

24. Yu. I. Belchenko, G. I. Dimov, and V. G. Dudnikov, Proc. of the Symposium on the Production and Neutralization of Negative Hydrogen Ions and Beams, Brookhaven National Laboratory report BNL 50727, 79 (1977).

25. K. Leung, et al., AIP Conf. Proc.158, Edit J.Alessi, p.356, 1986.

26. K.Leung, at.al. Rev.Sci.Instrum., 58 (2), 235 (1987).

27. V.Goretsky, et.al, Rev.Sci.Instrum., 73 (3),1157 (2002).

28. Akira Ueno, Kiyoshi Ikegami, Yasuhiro Kondo, Rev.Sci.Instrum., 75 (5), 1714 (2004).

29. P.Litvinov, I.Savchenko, A New Plasma $\mathrm{H}^{-}$Source. Proc. of the $7^{\text {th }}$ International Symposium on the Production and Neutralization of Negative Ions and Beams, AIP Conf. Proc No.380, 272 (1995). 
30. M.Bacal, Diagnostic Techniques for Negative Ion Source, Proc. of the $4^{\text {th }}$ International Symposium on the Production and Neutralization of Negative Ions and Beams, AIP Conf. Proc No. 158, 120 (1987).

31. A. Bruneteau, M. Bacal et.al. Proc. of the $7^{\text {th }}$ International Symposium on the Production and Neutralization of Negative Ions and Beams, AIP Conf. Proc No.380, 2261 (1995).

32. M. Seidl, H. Cui, J. Isenberg, H. Kwon, B. Lee, and S. Melnichuk, Negative surface ionization of hydrogen atoms and molecules, J. Appl. Phys.,79(6), 2896 (1996). 